\title{
Oviposition and Breeding Water Sites Preferences of Mosquitoes within Ojo area, Lagos State, Nigeria
}

\author{
Okwa 0 Omolade and Savage A. Adetutu \\ Department of Zoology and Environmental Biology, Lagos State University, Nigeria
}

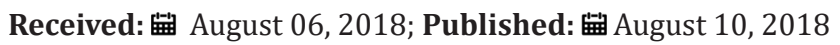

*Corresponding author: Okwa O Omolade, Department of Zoology and Environmental Biology, Lagos State University, Nigeria

\begin{abstract}
Introduction: Mosquitoes are slender, flying insects of the order diptera (true flies) in the arthropod Super-Phylum. They are deadly insects transmitting diseases such as malaria, elephantiasis and several arboviruses. The adaptability of mosquitoes is a problem and this is tantamount to greater spread of diseases. Malaria is the most widespread mosquito borne disease in Nigeria where it is holoendemic.
\end{abstract}

Aim: The source of malaria problem is the diverse breeding sites of mosquitoes. This work investigates preferred mosquito breeding water sites, physicochemical factors and colour cues influencing oviposition and development of mosquitoes.

Methods: Investigations were carried out on the preferred oviposition and breeding water sites of mosquitoes in the wild during the rainy season. $100 \mathrm{CL}$ of water were collected from five water samples each of packaged water, polluted water, pond water, tap water and rain water. The water samples were transferred to five green and five transparent containers (200CL) each and left opened in a well ventilated laboratory overnight for four weeks. Daily temperature and weekly Hydrogen ion concentration (ph) of the water in each container were taken.

Results: It was observed that mosquitoes oviposited in the ten containers continuously. The two mosquito genera identified were Anopheles and Culex specie using their developmental stages as morphotaxonomic indices. More Anopheles spp (57.2\%) oviposited than Culex spp (42.7\%) although this was not statistically significant. The polluted water had more Culex specie while the rain water had more Anopheles species with no regard for the colour of the container. Green colour did not serve as a significant cue for oviposition. Packaged water had the least mosquitoes of both species. There were no significant differences in temperature and $\mathrm{Ph}$ ranges of all sampled water in both containers.

Conclusion: Mosquito breeding occur right in homes as humans indulge in malariogenic lifestyles. Objects, excavations, plants and anything that can hold water must be eliminated. Water storage containers should always be covered. This work suggests control programmes must put into place preferred breeding sites of mosquitoes. Enforcement of environmental sanitation by cleaning drainages and open gutters around homes will go a long way. Education of the populace on mosquito breeding sites in homes is advocated.

Keywords: Mosquitoes; Anopheles; Culex; Oviposition; Breeding sites; Colour cues

\section{Introduction}

Mosquitoes are slender, fragile, flying insects of about 3-6mm in length belong to the family culicidae, order diptera (true flies) within the invertebrate super-Phylum arthropoda. They are poikilothermic and have amazing adaptability such as suctorial mouthparts, holometabolous life cycle and diversity which are some of the secrets behind their success. There are about 3500 species of mosquitoes in 40 genera [1]. Except in the Antarctica, Iceland, Faroe Islands, New Caledonia, Central Pacific islands, Seychelles, mosquitoes have been found everywhere [2,3]. Mosquitoes are biting nuisances although not all of them bite humans [4]. Some mosquitoes spread diseases more than wild fire! These diseases kill about 1 billion people yearly and are of public health concern [5]. No wonder, mosquitoes have been described as the deadliest creature on the earth [6]. However, not all mosquitoes are vectors
(Table 1). Africa is the home to three important, efficient and deadly mosquito genera which are Anopheles, Culex and Aedes species [5].

Both male and female mosquitoes feed on sugary and plant juices as source of energy, flight and dispersal. Only the female mosquitoes feed on blood which is required every 2-3 days for the maturation of its eggs as the plant sources are inefficient. Female mosquitoes mate once in a life time and require still waters to oviposit. This is a mandatory biological process [1]. Mosquitoes naturally infest ponds, marshes, puddles, swamps and other wetland habitats. Adult female mosquitoes may live up to a month in extreme cases in captivity but up to two weeks in nature. However, climatic factors have profound influences on mosquito's life span. Small variations in microclimate can affect mosquito 
chances of survival. Environmental factors as temperature, rainfall and humidity are important factors for mosquito development and longetivity [7]. A drop in temperate can change a mosquito life span by more than one week. Temperature has been regarded to be the most important factor [8]. This implies that, if temperature rises the larvae takes a shorter time to mature and more offspring are produced. In fact, temperature affects metamorphic changes in water [9].

Table 1: Common Mosquitoes Vectors and the diseases transmitted.

\begin{tabular}{|c|c|}
\hline Mosquito Genera & Diseases caused \\
\hline \multicolumn{2}{|c|}{ Sub -Family: Anophelinae } \\
\hline Anopheles species & Malaria, Filariasis, West Nile virus \\
\hline Bironella species (Australia) & Non-Vector \\
\hline Chagasia species & Non-Vector. \\
\hline \multicolumn{2}{|c|}{ Sub-Family: Culicinae } \\
\hline $\begin{array}{c}\text { Culex species } \\
\text { (Common house mosquito) }\end{array}$ & $\begin{array}{l}\text { Yellow fever, Filariasis, Japanese } \\
\text { encephalitis, St Louis encephalitis, } \\
\text { West Nile virus, Sindbis virus, Rift } \\
\text { valley fever, Ross river virus. }\end{array}$ \\
\hline $\begin{array}{l}\text { Aedes species } \\
\text { (Tiger mosquito) }\end{array}$ & $\begin{array}{c}\text { Dengue fever, Filariasis Zika virus, } \\
\text { Chikungunya virus, West Nile virus, } \\
\text { Mayaro virus, }\end{array}$ \\
\hline $\begin{array}{c}\text { Mansonia species } \\
\text { (Salt \& pepper mosquito) }\end{array}$ & $\begin{array}{l}\text { Filariasis, Dermatobia, Rift valley } \\
\text { fever, West Nile virus }\end{array}$ \\
\hline Psorophora species & $\begin{array}{l}\text { IIheus virus, Encephalitis, } \\
\text { Dermatobia }\end{array}$ \\
\hline $\begin{array}{c}\text { Culiseta melanura } \\
\text { (Black tailed mosquito) }\end{array}$ & Equine encephalitis \\
\hline Coquilletida species & $\begin{array}{l}\text { West Nile virus, Equine encephalitis } \\
\text { Filariasis }\end{array}$ \\
\hline Haemogogus species & $\begin{array}{c}\text { Mayaro virus, IIheus virus, Yellow } \\
\text { fever }\end{array}$ \\
\hline Uranotenia species & West Nile virus \\
\hline Ochlerotatus species & $\begin{array}{l}\text { St Louis encephalitis, Equine } \\
\text { encephalitis, West Nile virus, Sindbis } \\
\text { virus, Ross river virus, La Crosse } \\
\text { virus, Jamestone canyon virus. }\end{array}$ \\
\hline Sabethes species & $\begin{array}{l}\text { Yellow fever, St Louis encephalitis, } \\
\text { Ilheus virus }\end{array}$ \\
\hline Mimomyia species & West Nile virus \\
\hline Eretmapodites species & $\begin{array}{c}\text { Suspected for: Yellow fever, } \\
\text { Chikungunya virus, Rift valley fever }\end{array}$ \\
\hline Wyeomyia species & $\begin{array}{l}\text { Suspected for: IIheus virus, Equine } \\
\text { encephalitis \& Mugari virus }\end{array}$ \\
\hline Lutzia species & $\begin{array}{l}\text { Non -Vector (Mosquito larva eater) } \\
\text { suspected for Avian malaria }\end{array}$ \\
\hline Opifex species & Non-Vector, Not suspected yet \\
\hline $\begin{array}{l}\text { Toxorhynchites species } \\
\text { (Elephant mosquito) }\end{array}$ & $\begin{array}{l}\text { Non -Vector, Non-blood suckers } \\
\text { (Mosquito larva eater) }\end{array}$ \\
\hline
\end{tabular}

This also means that the frequency of sucking and digesting blood increases and this has grave implications for disease transmission [8]. Life inside the mosquito is a race against time. The time taken for the malaria parasite to go through its growth and development is close to the average life span of the mosquito itself. This period is longer in the temperate areas where the survival of the parasite is on the knife edge and temperature below certain point reduces the life span of the mosquito before it can transmit malaria [10]. Rainfall increases the breeding sites of mosquitoes and affects relative humidity. Biting intensity of mosquito reduces as rainfall reduces and can be suspended at low temperature. Vegetation increases resting sites and mosquito abundance could relate to vegetation cover [11]. Mosquitoes are believed to also have colour preferences depending on species and this influences oviposition sites [4,12]. It is a bad news that despite all the efforts to control mosquitoes, they are not threatened or on the verge of extinction [1].

Malaria is a problem in the tropics and not temperate countries. About $90 \%$ of malaria deaths occur in Sub-Sahara Africa with Nigeria and Democratic republic of Congo, the poorest country in the world carrying the greater burden [13]. Malaria is holoendemic in Nigeria [14], but most researchers do not take into account the menace of mosquito breeding sites and the attendant environmental factors. The source of the malaria problem in the tropics is mosquito adaptability to environmental conditions and diversity of breeding sites which is of great importance [15]. Control programmes must therefore put into place preferred breeding sites. In view of the above this work is aimed at:

a) Identifying water preferred by indigenous mosquitoes for oviposition and breeding.

b) Investigating the environmental factors influencing oviposition and development of the mosquitoes

c) Investigating the colour cues for oviposition and development of the mosquitoes

d) Advocate against malariogenic activities and proffer solution to eliminate mosquitoes in homes.

\section{Materials and Methods}

\section{Study Environment}

Lagos State is the former capital of Nigeria and still the commercial nerve centre of the country. It is the most populous state and home to every ethnic group in Nigeria. With a size of 3 , 577 square kilometers ( 24 sq metres with about $71 / 2$ sq miles) representing $0.4 \%$ of the country. It is the smallest state in the federation, $22 \%$ of 787 square kilometers is made up of lagoons and Creeks. The urban city of Lagos has tidal swamps breeding enormous species of mosquitoes. Lagos State University (LASU), Ojo campus is situated in Ojo area on the Lagos- Badagry express way. At the time of this survey, the area facing the campus was undergoing some environmental modifications due to the road construction on the express way. The work was conducted in the Zoology and Environmental Biology (ZEB) laboratory of the University, in the rainy season June-July, 2017. There were many puddles around the Faculty of Science, where the ZEB laboratory is located. 


\section{Selection of Containers}

200 CL plastic buckets with a diameter of $20 \mathrm{~cm}$ were used as containers to study the oviposition preference of mosquitoes according to the Vijayakar et al. [16]. Green buckets were chosen because mosquitoes have been reported to have colour cues for oviposition such as green colour $[12,16]$. Similarly, adult mosquitoes mostly rest on green vegetable during the day. Okorie [17] also reported that mosquitoes love cool shade for oviposition. The transparent buckets were selected as a contrast to the green buckets and for more visibility in observing the developmental stages of mosquitoes for identification.

\section{Collection of sample water}

Packaged water: Two De Robin Sachet water (60CL) were obtained within the campus, Pond water was collected from LASU fish pond, Tap water from ZEB laboratory, Polluted water from a gutter at Iyana Iba near LASU, Rain water was collected during rainfall. Using a measuring cylinder, $100 \mathrm{CL}$ of each was deposited in the five green containers and five transparent containers respectively.

\section{Identification, observation and counting of Mosquitoes}

Containers were examined daily for mosquito larvae. Daily oviposition and larva in each container were counted daily and recorded. Observations were made on the eggs, larvae and pupae and recorded. Eggs and larva identification to identify the type of mosquito genera, was aided by morphotaxomic keys according to Harbach [18] and Oyerinde [19] with the following questions in mind.

a) Were the eggs laid in rafts?

b) Were the eggs with floats?

c) Does the larva has a siphon or not and lie parallel to the surface or hang vertically?

d) Does the adult lie parallel to the surface water or at an angle of $45^{\circ}$ ?

Physicochemical parameters: Water temperature $\left({ }^{\circ} \mathrm{C}\right)$ in each container was monitored daily with mercury in glass thermometer and the Hydrogen ion concentration $\left(\mathrm{P}_{h}\right)$ was monitored with a Hunna scientific Ph meter.

\section{Statistical Analysis}

Daily oviposition counts were calculated as the percentage of oviposition for each container. Average temperature and $\mathrm{Ph}$ ranges were calculated. Chi square $\mathrm{X} 2$ was used to determine the Table 2: Identification and counting of larvae within four weeks of exposure.

\begin{tabular}{|c|c|c|c|c|c|c|}
\hline \multicolumn{4}{|c|}{ Green Containers } & \multicolumn{3}{c|}{ Transparent Containers } \\
\hline Sample Water & Culex (\%) & Anopheles (\%) & Both (\%) & Culex (\%) & Anopheles (\%) & Both (\%) \\
\hline Packaged & $24(4.41)$ & $141(19.2)$ & $165(12.9)$ & $47(8.68)$ & $100(13.9)$ & $147(11.6)$ \\
\hline Polluted & $250(45.9)$ & $51(6.95)$ & $301(23.5)$ & $211(39.0)$ & $33(4.58)$ & $244(19.3)$ \\
\hline Pond & $205(37.6)$ & $156(21.2)$ & $361(28.2)$ & $194(35.8)$ & $182(25.3)$ & $376(29.8)$ \\
\hline Tap & $48(8.82)$ & $130(17.7)$ & $178(13.9)$ & $67(12.3)$ & $100(13.9)$ & $167(13.2)$ \\
\hline Rain & $17(3.12)$ & $255(34.7)$ & $272(21.2)$ & $22(4.06)$ & $304(42.2)$ & $326(25.8)$ \\
\hline ALL & $544(42.5)$ & $733(57.4)$ & $1277(50.3)$ & $541(42.9)$ & $719(57.0)$ & $1260(49.6)$ \\
\hline
\end{tabular}

Cite this article: Okwa 0 Omolade, Savage A. Adetutu. Oviposition and Breeding Water Sites Preferences of Mosquitoes within Ojo area, Lagos State, Nigeria. Biomed J Sci\&Tech Res 7(5)- 2018. BJSTR MS.ID.001565. DOI: 10.26717/ BJSTR.2018.07.001565.

differences in results between the water sample sites in the green and transparent containers. $\mathrm{P}<0.05$ was regarded as an acceptable level of significance while $\mathrm{P}>0.05$ was not significant at $5 \%$.

\section{Results and Observations}

\section{Mosquito Abundance}

The ten containers generally tend to be relatively favorable for the oviposition and breeding of the two mosquito genera identified. The breeding was continuous throughout the four weeks of investigation. Mosquito oviposited more in the green containers $(50.3 \%)$ than the transparent containers (49.6\%). This was however not statistically significant $(\mathrm{P}>0.05)$. There were more Anopheles spp than Culex spp in green containers (57.4\%) as well as the transparent ones (57.0\%). This implies that more Anopheles spp (57.2\%) oviposited than Culex spp (42.7\%) although this was not statistically significant $(\mathrm{P}>0.05)$. Mosquitoes oviposited more in pond water in both the green container $(28.2 \%)$ and transparent container $(29.8 \%)$. Packaged water had the least mosquitoes in both green containers (12.9\%) and transparent ones (11.6\%). This difference between the oviposition rates of the pond and packaged sample waters was statistically significant $(\mathrm{P}<0.05)$ as shown in Table 2. Generally, eggs of both mosquitoes' genera were observed right from the first day after leaving the containers open overnight. Both hatched within 2-3 days, the larvae between 2-5 days and pupae hatched 2-4 days. Stages between larvae moulted four times in instars. The larvae got bigger and darker from the first to fourth instar which becomes the pupae stage. The adults (Imago) rest on the surface for a short time and dry up and were observed flying away from the containers.

\section{Anopheles Species Distribution}

Up to 1452 of Anopheles spp eggs (57.2\% of eggs) were laid overnight within four weeks. Anopheles spp preferred mostly the rain water for oviposition both in the green container (34.7\%) and transparent one (42.2\%).) Anopheles spp mosquito oviposited the least in polluted water in the green container (6.95\%) as well as the transparent container (4.97\%). In terms of preferred colour the results were not statistically significant $(\mathrm{P}>0.05)$ when compared as shown in Table 2 The boat shaped eggs were laid separately in floats. They were tiny and whitish as view from the transparent containers. The larva has no siphon and positioned themselves to lie parallel to the surface of water (Figures 1-3). The pupae hatched 2-3 days. They were greenish with wide respiratory trumpets. The adults were lying at an angle to the water and had delicate legs (Figure 1). 


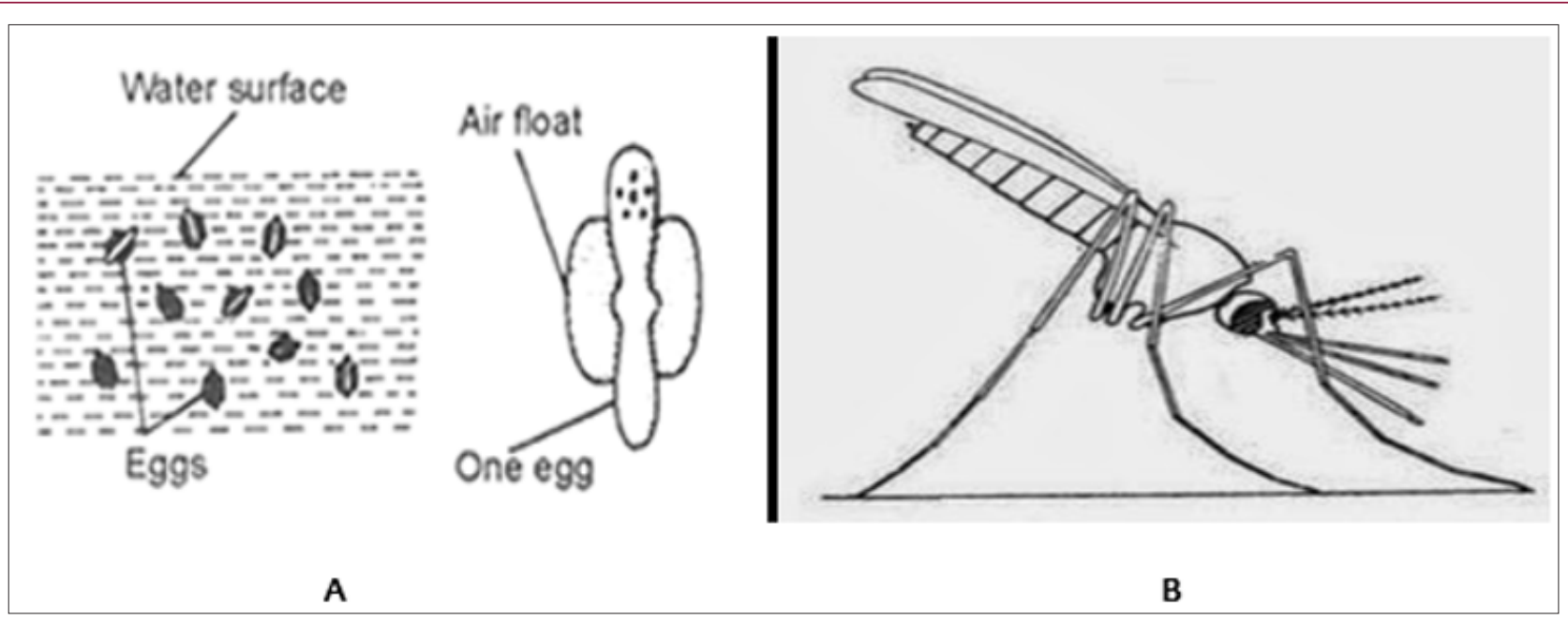

Figure 1: Anopheles eggs, Anopheles Adult.

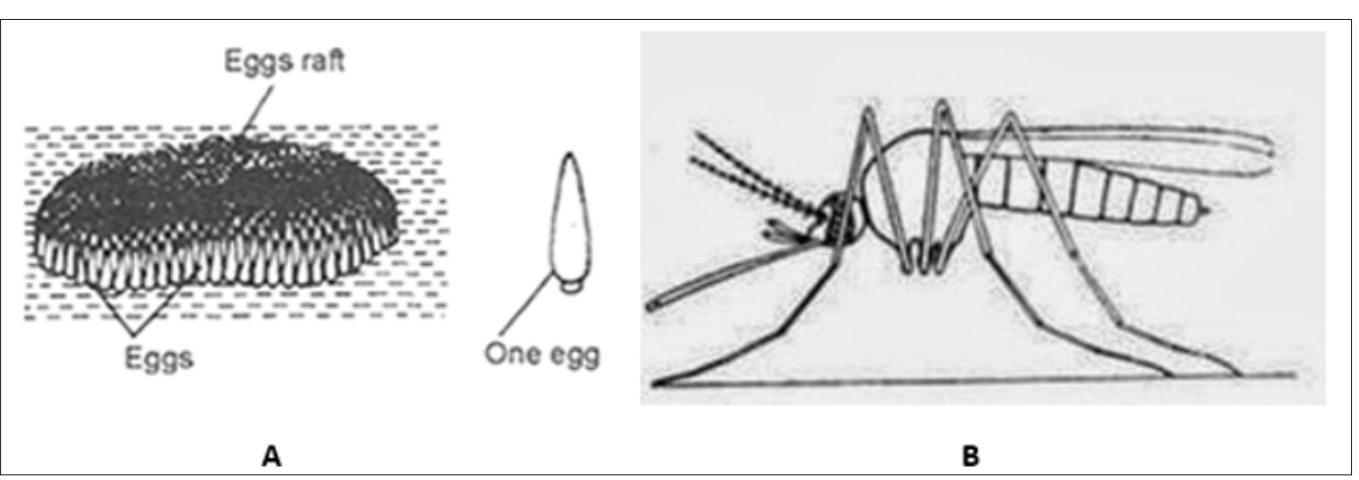

Figure 2: Culex eggs, Culex Adult.

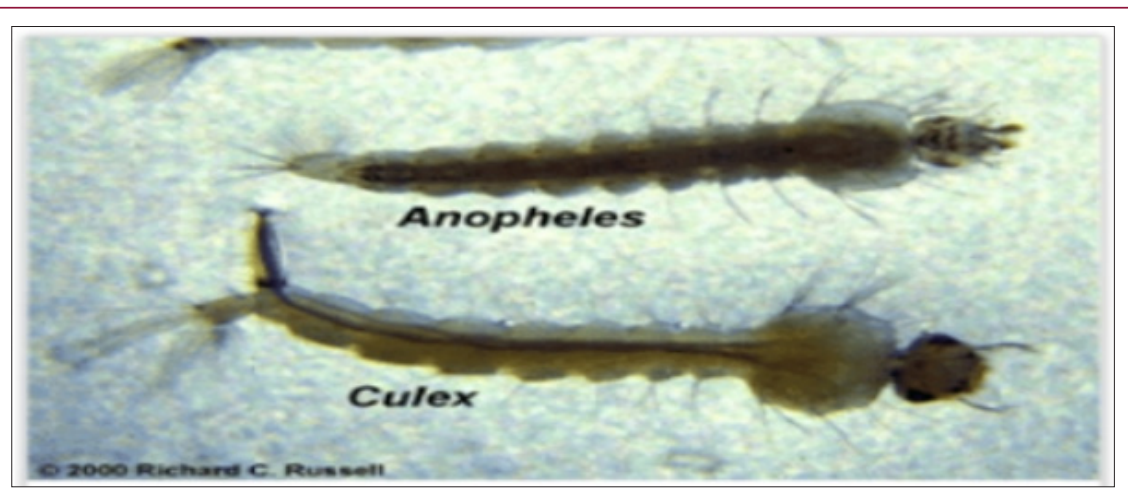

Figure 3: Mosquito larvae stages of Anopheles and Culex species.

\section{Culex species Distribution}

Up to 1085 of Culex spp eggs ( $42.7 \%$ of eggs) were laid overnight within four weeks. Culex spp preferred mostly the polluted water for oviposition in both the green container (45.9\%) and the transparent container (39\%). On the contrary, rain water was the least preferred in both green container $(3.12 \%)$ and transparent one $(4.06 \%)$. In terms of preferred colour the results were not statistically significant $(\mathrm{P}>0.05)$ when compared as shown in Table 2. The cigar shaped eggs were laid in 20 rafts of up to ten with no floats. The larvae were observed after 2 days. Larvae with siphon hanged vertically downwards (Figure 3). The comma shaped pupae were observed 2 days after. They were colorless, long and narrow with respiratory trumpets. They swim to the surface to breathe. The adults were parallel to the water surface and had stouter legs 10-14 days (Figure 2).

\section{Physico-chemical parameters}

There were no significant differences in temperature and $\mathrm{Ph}$ ranges in the green and transparent containers $(\mathrm{P}>0.05)$ as shown in Table 3 below. Average temperature ranges from 26.86-28.10 c. All the sampled water in both containers was slightly alkaline as the ranges from $7.9-8.77$ throughout the 4 weeks exposure. 


\section{Discussion}

In this study, the occurrence of Anopheles and the Culex species stages in plastic containers is of public health significance. This work has suggested that the source of mosquito problem can be just about anywhere where water collects or is stored in homes. In residential areas, several places and human activities (malariogenic activities) create mosquito breeding sites as discarded trash cans, open buckets, clogged gutters, abandoned vehicles, tires, drainages, ditches, natural depressions, or just anywhere that can retain water. Mosquito goes through 4 stages during its life cycle. The first 3 stages egg/ larva / pupa are aquatic and last 5-14 days depending on the species and ambient temperature [10]. The ability of mosquitoes to thrive even outside their natural habitat makes them a nuisance to mankind. Inside homes, endophilic female mosquitoes rest in dark places, corners of rooms, behind curtains but the exophilic biters rest on vegetation after feeding. When the eggs are about to be laid they go into suitable water to oviposit.

Table 3: Average weekly Temperature range $\left({ }^{\circ} \mathrm{C}\right)$.

\begin{tabular}{|c|c|c|}
\hline Sample Water & $\begin{array}{c}\text { Green containers } \\
\left({ }^{\circ} \mathbf{C}\right)\end{array}$ & $\begin{array}{c}\text { Transparent } \\
\text { containers }\left({ }^{\circ} \mathbf{C}\right)\end{array}$ \\
\hline Packaged & $27.24-27.67$ & $26.86-28.0$ \\
\hline Polluted & $27.24-27.81$ & $26.86-27.86$ \\
\hline Pond & $27.51-27.95$ & $26.86-27.86$ \\
\hline Tap & $27.48-27.90$ & $27.14-28.0$ \\
\hline Rain & $27.26-27.60$ & $26.74-28.1$ \\
\hline
\end{tabular}

Table 4: Average weekly hydrogen ion concentration $(\mathrm{Ph})$.

\begin{tabular}{|c|c|c|}
\hline Sample Water & $\begin{array}{c}\text { Green containers } \\
\text { Ph }\end{array}$ & $\begin{array}{c}\text { Transparent } \\
\text { containers } \\
\mathbf{P h}\end{array}$ \\
\hline Packaged & 8.0 & 8.13 \\
\hline Polluted & 8.77 & 8.7 \\
\hline Pond & 8.37 & 8.7 \\
\hline Tap & 8.43 & 8.57 \\
\hline Rain & 8.0 & 7.9 \\
\hline Average & 8.31 & 8.4 \\
\hline
\end{tabular}

Prevailing physicochemical parameters in habitats are important factors for the survival and development of mosquitoes.

In a study in Sri Lanka by Amerasinghe et al. [20], significant association was found between different habitats, specific physicochemical parameters and mosquito abundance. In this work the $P_{h}$ range of all sampled water was slightly alkaline throughout. According to Amerasinghe et al. [20], alkalinity is associated with high carbon-dioxide content of water. Okorie [17] reported that water temperature of $27^{\circ} \mathrm{C}$ is ideal for mosquito breeding, while Amerasinghe et al. [20], reported a temperature of $28^{\circ} \mathrm{C}$ as ideal. However, both temperatures fell in line with the average temperature ranges $26-86-28.1^{\circ} \mathrm{C}$ in this work. Naturally mosquitoes breed in surface waters of $P_{h}$ 6.5- 8.5 [10]. The WHO standard for best quality water is a neutral $p_{h}[21]$ and only the $P_{h}$ of rain water should be rightly inserted after closer to i.e was closer to this in this study. In a study by Munga et al. [22], Anopheles mosquito oviposited significantly more in rain water as it prefers water with few impurities for oviposition. Anopheles gambiae prefers clean clear water such as rainwater and pools with near neutral $\mathrm{pH}$ [9]. This observation is similar to the result of this work. Past studies reported that there was more Culex in Ojo area than Anopheles [23] but there was insignificantly more Anopheles oviposition than Culex under laboratory conditions in this present study.

Okogun et al. [11] reported that Culex requires only an inch of stagnant water to lay eggs with preference for open septic tanks, gutters, drainages, trenches and soak-aways. Culex spp larvae feed on microbes, algae and organic matter so they prefer polluted water which favors their feeding requirements [1]. Okorie [17] also reported that Culex spp prefers water with organic matters and are no respecters of good clear water as corroborated by this present study. Mosquitoes have been reported as hating and loving certain colours. According to Collins and Blackwell [24], mosquitoes hate yellow lights in front of houses but love ultra-violet lights and blue lights. Studies have showed that they are attracted to people wearing dark colours. [12] had reported that colour cues serve as oviposition attractant and stimulant as Aedes aegypti mosquito responded to green colour in his study. In a study by Collins and Blackwell [4], black and red containers colour was significantly preferred for oviposition of Toxorhynchites species, the larviparous mosquito. In this study, green colour did not serve as a significant colour cue for oviposition for both Anopheles and Culex. There is a relationship between the environment and mosquito abundance [3]. Mosquito can adapt to environmental changes and water pollution [24].

Today's mosquito breeds even where we think they can never thrive due to environmental changes. The adaptability of mosquitoes and the ability to thrive in variety of habitats is a problem and this is tantamount to greater spread of diseases. Temporal and spatial changes in temperature, precipitation and humidity under different climatic conditions will affect the biology and ecology of mosquitoes and consequently the risk of disease transmission [15]. Small changes in temperature result in large differences in availability and development. Changes in the local environment are important as they create or reduce the number of suitable breeding sites for vectors so affecting their abundance and transmission pattern [7]. Rainfall also plays a role in mosquito ecology as it increases the availability of surface water and affects relative humidity and hence longetivity of the adult mosquito [10]. We did not observe Aedes mosquito because they prefer to lay eggs on damp soil flooded by water, tree holes, and axils of plants. It is pertinent to said that the type of water in which mosquito larvae are found helps in the identification of the species $[25,26]$.

\section{Conclusion}

[27] reported that Nigeria loses about 1.1 trillion naira annually to control malaria. A lot of money is spent on drugs, insecticides and mosquito nets. Scientist also have to deal with diversity of mosquito species [14]. It will be cost-effective to deal with mosquitoes by nipping them in the bud through eliminating their source. Malaria 
is the number one killer disease in Nigeria where unfortunately, it is called "common" malaria. This is an irony; malaria death has been described by an expert as causing death more than the deaths due to the first and second world wars! [1]. Man and environment are created to interact with each other on a balance basis but man has failed in its duty to the environment. The responsibility of man is to respect, protect and care for the environment. By sheer negligence, mosquito breeds just under our nose so house spraying and screening is inadequate. People store water in containers in homes because of poor water supply. Malariologist will benefit if the source of mosquito breeding sites are located and destroyed. This will reduce the transmission threshold of malaria. This work has contributed to the growing body of data on mosquito oviposition and the influence of external cues. This will form a baseline data for Mosquitoes in Ojo area of Lagos, Nigeria. As ecosystems are being modified across the planet, the habitat is altered and malaria territories are being extended because of global warming. Mosquito borne diseases will not be readily controlled if we continue to ignorantly breed mosquitoes domestically.

\section{Recommendations:}

a) Dispose unused containers, place useful ones upside down under a roof or seal with a tight cover.

b) Change frequently water troughs of pet animals and garden flower pots

c) Keep trash cans tightly sealed and drill a hole at the bottom in order not to retain water

d) Fill up eroded soils, natural depressions and excavations and empty rain filled receptacles

e) Swimming pools in homes should not be left unused and untreated.

f) Outdoor spraying of domestic animal shelters, garages, outdoor latrines and tree hole fillings.

g) Spray oil on stagnant pools to kill mosquito aquatic stages.

h) Drainage system, ditches and gutters must not be dumped with waste to avoid clogging

i) Take action to prevent sewage effluents, soak-away, domestic run offs and empty soft drink bottles from becoming breeding sites.

j) Adherence to basic architectural designs, house designs with excavations or rain filled receptacles should be discouraged such as the Eave tube technology in Benue State, Nigeria [28].

k) Health and environmental education of the populace on preventing domestic mosquito breeding.

l) Environmental sanitation should be everybody's business and the government should enforce it.

\section{References}

1. Awolola TS (2017) Malaria, Mosquitoes and Man: The battle continues! Nigeria institute of Medical Research (NIMR). Distinguished lecture series ( $7^{\text {th }}$ Edn.) p. 73.
2. Gillet JD (1972) Common Africa mosquitoes and their medical importance: William Heinmann Medical book. Limited London p. 106.

3. Chapman HC (2000) Biological control of mosquitoes. Tropical Medicine and International Health 10: 888-893.

4. Collins LE, Blackwell A (2000) Colour cues for oviposition behavior in Toxorhynchites moctezuma and T. amboinensis mosquitoes. Journal of Vector Ecology 25(2): 127-135.

5. WHO (2014) World malaria Report. World Health Organization, Geneva, USA, p. 242.

6. WHO (2015) Global strategy for Dengue prevention and control. World Health Organization, Geneva, USA, p. 43.

7. Becker N, Petrič D, Zgomba M, Boase C, Madon M, et al. (2010) Mosquitoes and their control (2nd edition) Heidelberg, Germany.

8. Howlett F (1910) The influence of temperature upon the biting of mosquitoes. Parasitology 3(4): 479-481.

9. Kelly-Hope LA, Hemingway J, Mackenzie FE (2009) Environmental factors associated with malaria vectors Anopheles gambiae and Anopheles funestus in Kenya. Malaria Journal 8: 268.

10. Osta FM, Burket TR, Andre RJ (2004) Behavioral aspects of Mosquito. Annual Revision of Entomology 34: 401-421.

11. Okogun GRA, Nwoke BEB, Okere AN, Anosike JC, Esekhegbe AC, et al. (2013) Epidemiological implications of preferences of breeding sites of mosquito species in Mid- western Nigeria. Annual Agricultural and Environmental Medicine 10(2): 217-222.

12. Beckel WE (1955) Oviposition site preference of Aedes mosquito (Culicidae) in the laboratory, Mosquito News 15: 224-228.

13. WHO (2008) Global burden of diseases: 2004 Update. World Health Organization, Geneva, USA, p. 160.

14. Okwa 00 (2012) Malaria, a pending problem in sub Saharan Africa. In: Malaria Parasites In-tech open access publisher p. 350.

15. Beck-Johnson LM, Nelson WA, Paaijmans KP, Read AF, Thomas MB, et al. (2013) The effect of temperature on Anopheles mosquito dynamics and potential for malaria transmission. PLOS One 8: 79276.

16. Vijayakar K, Sudheesh TK, Zima N, Farook U, Anu K, et al. (2014) A study of container breeding mosquitoes with special reference to Aedes (S) aegypti and A. albopictus in India. Journal of Vector Borne Disease 51(1): 27-32.

17. Okorie TG (1978) The breeding sites preferences of mosquitoes in Ibadan, Nigeria. Nigeria journal of Entomology 1(3): 71-80.

18. Harbach R (2008) Family Culicidae (Meigen 1818): Mosquito taxonomic inventory.

19. Oyerinde JPO (1999) Essentials of Tropical Medical Parasitology. University of Lagos Press, Akoka p. 435.

20. Amerasinghe FP, Indrajith NG, Ariyasena TG (1995) Physicochemical characteristics of mosquitoes breeding habitats in an irrigation development area in Sri-Lanka. Cey Journal of Science 24(2): 13-29.

21. WHO (2010) Developing guidelines for water, sanitation and hygiene promotion in schools. World Health Organization Geneva, USA, p. 60.

22. Munga S, Minakawa N, Zhou G, Okeyo-Owuor JB, Githeko AK, et al. (2005) Report of the Entomological Society of America.

23. Okwa 00, Sulaimon R (2004) Dynamics of the transmission of Malaria in Ojo local Government area of Lagos Nigeria. Journal of Research and Review in Science 3: 1-6.

24. Awolola TS, Oduola AO, Obansa JB, Chukwura NJ, Unyimordu JP, et al. (2007) Anopheles gambiae breeding in polluted water in urban Lagos, South western Nigeria. Journal of Vector Borne Diseases 44(4): 181-888.

25. Centre for disease control : CDC ( 2004) Malaria Report 
26. WHO (2013) World malaria Report. World Health Organization, Geneva, USA, p. 284.

27. Federal Ministry of Health (2008) Nigeria Mosquito Control Programme. Federal Ministry of Health, Abuja.

ISSN: 2574-1241

DOI: 10.26717/BJSTR.2018.07.001565

Okwa O Omolade. Biomed J Sci \& Tech Res

cC (i) This work is licensed under Creative

Submission Link: https://biomedres.us/submit-manuscript.php
28. Aju-Ameh OC, Awolola TS, Mwansat GS, Mufuyau HB (2017) Flaws in house design that aid Mosquito invasion of human habitat and malaria transmission. Journal of Environmental Science, Toxicology and Food Technology 11: 61-69.

BIOMEDICAL
RESEARCHES $\quad \begin{aligned} & \text { Assets of Publishing with us } \\ & \text { - Global archiving of articles }\end{aligned}$

